Article

\title{
Projecting Lifetime Health Outcomes and Costs Associated with the Ambient Fine Particulate Matter Exposure among Adult Women in Korea
}

\author{
Gyeyoung Choi ${ }^{1}$, Yujeong Kim ${ }^{1,2}$, Gyeongseon Shin ${ }^{1}$ and SeungJin Bae ${ }^{1, * \mathbb{D}}$ \\ 1 College of Pharmacy, Ewha Womans University, Seoul 03760, Korea; 191ipg02@ewhain.net (G.C.); \\ cmind96@naver.com (Y.K.); sunny628@g.ewha.ac.kr (G.S.) \\ 2 Korean Health Insurance Review \& Assessment Service, Wonju 26465, Korea \\ * Correspondence: sjbae@ewha.ac.kr
}

check for updates

Citation: Choi, G.; Kim, Y.; Shin, G.; Bae, S. Projecting Lifetime Health Outcomes and Costs Associated with the Ambient Fine Particulate Matter Exposure among Adult Women in Korea. Int. J. Environ. Res. Public Health 2022, 19, 2494. https:// doi.org/10.3390/ijerph19052494

Academic Editor: William A Toscano

Received: 16 December 2021 Accepted: 17 February 2022 Published: 22 February 2022

Publisher's Note: MDPI stays neutral with regard to jurisdictional claims in published maps and institutional affiliations.

Copyright: (C) 2022 by the authors. Licensee MDPI, Basel, Switzerland. This article is an open access article distributed under the terms and conditions of the Creative Commons Attribution (CC BY) license (https:// creativecommons.org/licenses/by/ $4.0 /)$.

\begin{abstract}
We sought to estimate the lifetime healthcare costs and outcomes associated with the exposure to the escalated concentration of fine particulate matter (particle size $<2.5 \mu \mathrm{m}, \mathrm{PM}_{2.5}$ ) among adult Korean women. We adapted a previously developed Markov model, and a hypothetical cohort composed of Korean women was exposed to either a standard $\left(15 \mu \mathrm{g} / \mathrm{m}^{3}\right)$ or increased $\left(25 \mu \mathrm{g} / \mathrm{m}^{3}\right)$ concentration of $\mathrm{PM}_{2.5}$. The time horizon of the analysis was 60 years, and the cycle length was 1 year. The outcomes were presented as direct healthcare costs and quality-adjusted life years (QALYs), and costs were discounted annually at 5\%. Deterministic and probabilistic sensitivity analyses were performed. The model estimated that when the exposure concentration was increased by $10 \mu \mathrm{g} / \mathrm{m}^{3}$, the lifetime healthcare cost increased by USD 9309, which is an $11.3 \%$ increase compared to the standard concentration group. Women exposed to a higher concentration of $\mathrm{PM}_{2.5}$ were predicted to live 30.64 QALYs, compared to 32.08 QALYs for women who were exposed to the standard concentration of $\mathrm{PM}_{2.5}$. The tendency of a higher cost and shorter QALYs at increased exposure was consistent across a broad range of sensitivity analyses. The negative impact of $\mathrm{PM}_{2.5}$ was higher on cost than on QALYs and accelerated as the exposure time increased, emphasizing the importance of early intervention.
\end{abstract}

Keywords: fine particulate matter; $\mathrm{PM}_{2.5}$; healthcare cost; QALYs; Markov model

\section{Introduction}

Air pollution represents one of the biggest environmental risks to health [1]. In 2012, more than three million deaths were attributable to ambient air pollution [2]. Among the pollutants, particulate matter with the diameter less than $2.5 \mu \mathrm{m}\left(\mathrm{PM}_{2.5}\right)$ is known to be associated with the increased morbidity and mortality of various diseases [3]. $\mathrm{PM}_{2.5}$ penetrates within the respiratory tract and circulates in the blood stream due to its small size. As a result, $\mathrm{PM}_{2.5}$ affects not only the respiratory system but also the cardiovascular system and can cause various health problems. In fact, $\mathrm{PM}_{2.5}$ was the fifth leading cause of death worldwide following high blood pressure and smoking [4].

The World Health Organization (WHO) Air Quality Guidelines (AQGs) has recommended an annual average $\mathrm{PM}_{2.5}$ concentration of $10 \mu \mathrm{g} / \mathrm{m}^{3}$ as the target value and three interim targets (IT; IT-1 $35 \mu \mathrm{g} / \mathrm{m}^{3}$, IT-2 $25 \mu \mathrm{g} / \mathrm{m}^{3}$, IT-3 $15 \mu \mathrm{g} / \mathrm{m}^{3}$ ), which have been shown to be achievable with successive and sustained abatement measures [5]. These concentrations were chosen based on the significance of their effect on survival, where the AQG target value was the lowest level at which the total, cardiopulmonary, and lung cancer mortality were shown to increase with more than $95 \%$ confidence in response to $\mathrm{PM}_{2.5}$ in the American Cancer Society study. In South Korea, the $\mathrm{PM}_{2.5}$ level has been continually maintained over the guideline value since 2015 when the South Korean government started the official observation of $\mathrm{PM}_{2.5}$ [6]. However, due to geographical and seasonal reasons, 
the airborne fine particulate matters from foreign high-emission areas add to the burden of domestic pollution [7]. Therefore, despite the efforts of the government to manage the annual concentration, the potential negative health effects of $\mathrm{PM}_{2.5}$ have been of great concern among the Korean people.

Though there have been many studies reporting an increased disease risk associated with the elevated $\mathrm{PM}_{2.5}$ [8-11], studies projecting the lifetime economic effect of diseases due to $\mathrm{PM}_{2.5}$ are limited. In an economic burden of disease study performed in 111 cities, the total economic cost caused by particulate matter pollution in 2004 was estimated to be approximately USD 29,178.7 million [12]. If the concentration of $\mathrm{PM}_{2.5}$ decreases by $10 \mu \mathrm{g} / \mathrm{m}^{3}$, more than USD 22 million of economic benefit will occur annually in Seoul, South Korea [13]. Moreover, life expectancy will be lengthened by 0.35 years [14]. However, there have been no studies estimating the lifetime cost and a much lower quality of life, which is reported to be significantly affected by $\mathrm{PM}_{2.5}$ exposure $[15,16]$. The purpose of this study was to estimate the economic and health outcomes of ambient $\mathrm{PM}_{2.5}$ exposure for a lifetime among Korean women.

\section{Materials and Methods}

\subsection{Markov Model}

We have adopted a previously developed Markov state-transition model to simulate the natural history of $\mathrm{PM}_{2.5}$ exposure (Figure 1) [17]. At the start of the model, the cohort was exposed to either standard or increased concentration of $\mathrm{PM}_{2.5}$. Subsequent Markov model pathways were same with four diseases and their corresponding health states. The whole cohort started from event-free health state and transferred to each health state according to the probabilities derived from reference data. All health states were mutually exclusive and collectively exhaustive so the patients could be assigned to only one health state at any given time $[18,19]$.

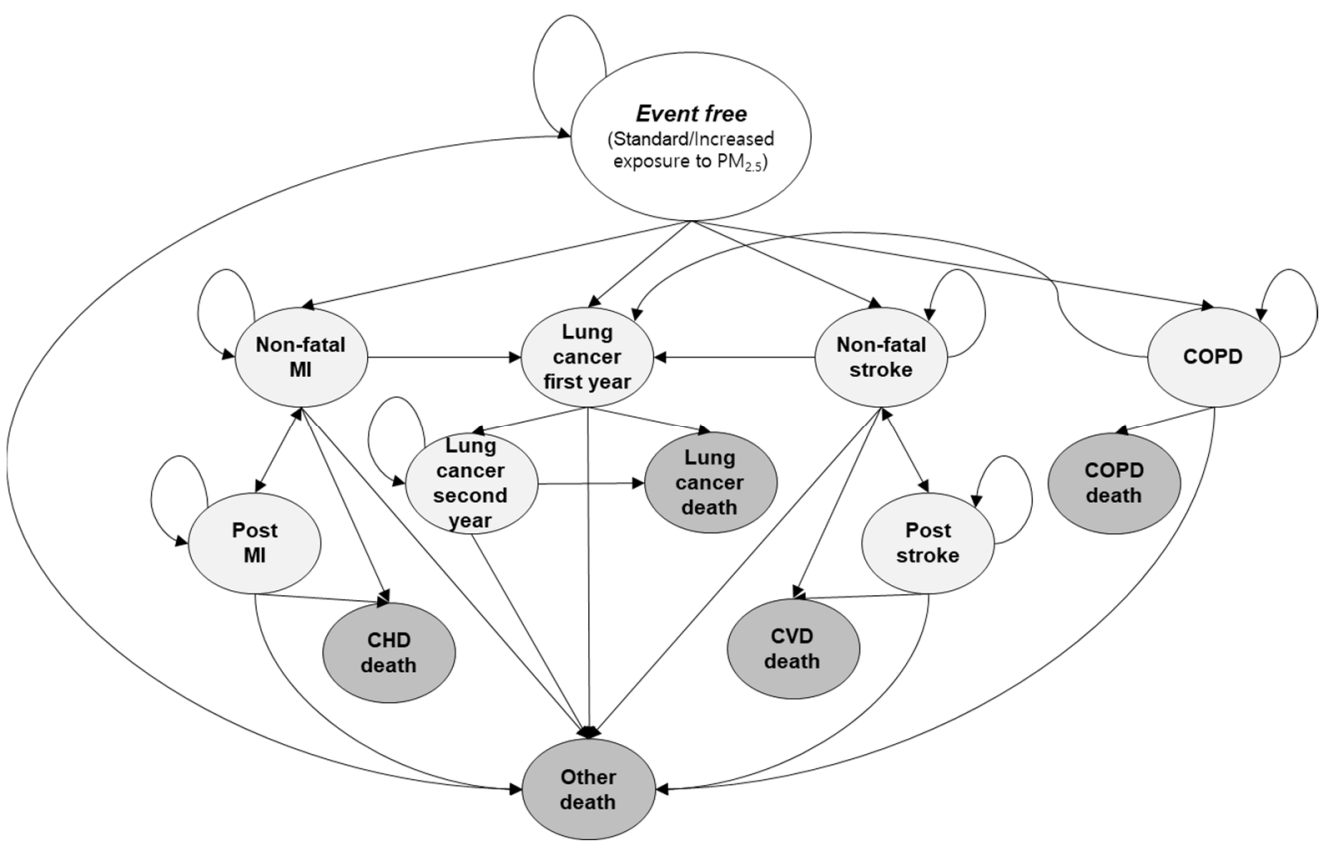

Figure 1. Health states and disease progression for Korean adult women who are exposed to ambient $\mathrm{PM}_{2.5}$. CHD, coronary heart disease; CVD, cardiovascular disease; MI, myocardial infarction.

The four diseases, lung cancer, myocardial infarction, stroke, and COPD, were selected based on previous systematic reviews and official reports, in which those diseases were named as some of the most affected diseases due to $\mathrm{PM}_{2.5}$ exposure [1,20-23]. Of these four diseases, myocardial infarction, stroke, and COPD were further sorted by progression period (e.g., first year and following years) because transition probabilities, quality of life, 
and treatment cost vary significantly [24-26]. To investigate the long-term effect of $\mathrm{PM}_{2.5}$ exposure, the analysis period was 60 years, and the cycle length was 1 year. The outcomes were presented as US dollars (USD) and QALYs, and the costs were discounted at 5\% annually to reflect people's positive time preference $[27,28]$. TreeAge Pro ${ }^{\circledR} 2020$ software was used to build the simulation model.

\subsection{Target Population}

A hypothetical cohort of 10,000 Korean women aged 40 years old was analyzed. We targeted middle-aged women because many previous studies on $\mathrm{PM}_{2.5}$ have been performed targeting middle-aged female population $[29,30]$. To assess the cost and health risk of increased exposure of $\mathrm{PM}_{2.5}$, the study population was assumed to be consistently exposed to either increased or standard concentration of $\mathrm{PM}_{2.5}$. Increased concentration was defined as $25 \mu \mathrm{g} / \mathrm{m}^{3}$, which is the average annual $\mathrm{PM}_{2.5}$ concentration of South Korea in 2017 [6]. Standard concentration was set to $15 \mu \mathrm{g} / \mathrm{m}^{3}$, which is the interim target 3 (IT-3) concentration of $\mathrm{PM}_{2.5}$ established by $\mathrm{WHO}$.

\subsection{Input Data}

A systematic review was performed to obtain the increased risk of disease incidence due to $\mathrm{PM}_{2.5}$ exposure (Supplementary Materials) [31]. Firstly, the search terms and PICO (population, intervention, comparison, outcomes) were set, and then we searched through PubMed and conducted an additional search in Google Scholar. The search strategy is shown in Table 1. After the search of electronic database, detailed criteria such as the age of the population or exposure concentration to $\mathrm{PM}_{2.5}$ were checked by two authors (G.C, Y.K) Any disagreement between the two authors over the eligibility of studies was resolved through discussion with a third author (G.S). Data extraction included sample size of study, age, gender, $\mathrm{PM}_{2.5}$ exposure status, $\mathrm{PM}_{2.5}$ concentration increment, and outcomes (relative risk). Cohort studies with large sample size were preferred and final selection was based on the similarity of the study cohort to our target population.

Table 1. Search strategy for the systematic review of relative risks of diseases used in the model.

\begin{tabular}{|c|c|}
\hline Step & Search Strategy \\
\hline \#1 & woman or female \\
\hline \#2 & particulate matter or $\mathrm{PM}_{2.5}$ \\
\hline \multicolumn{2}{|c|}{ Lung Cancer } \\
\hline \#3 & lung cancer or lung carcinoma \\
\hline$\# 4$ & \#1 and \#2 and \#3 \\
\hline \#5 & $\begin{array}{c}\# 1 \text { and \#2 and \#3 and (relative risk or hazard ratio) and } \\
\text { (incidence rate or prevalence or mortality) }\end{array}$ \\
\hline \#6 & Filters: English, Korean, Adult: 19+ years \\
\hline \multicolumn{2}{|c|}{ Myocardial Infarction } \\
\hline \#3 & $\begin{array}{c}\text { myocardial infarction or cardiovascular disease or ischemic } \\
\text { heart disease or coronary heart disease }\end{array}$ \\
\hline$\# 4$ & \#1 and \#2 and \#3 \\
\hline \#5 & $\begin{array}{c}\# 1 \text { and \#2 and \#3 and (relative risk or hazard ratio) and } \\
\text { (incidence rate or prevalence or mortality) }\end{array}$ \\
\hline \#6 & Filters: English, Korean, Adult: 19+ years \\
\hline \multicolumn{2}{|l|}{ Stroke } \\
\hline \#3 & $\begin{array}{c}\text { stroke or cerebrovascular disease or cerebral hemorrhage or } \\
\text { cerebral infarction }\end{array}$ \\
\hline$\# 4$ & \#1 and \#2 and \#3 \\
\hline \#5 & $\begin{array}{c}\# 1 \text { and \#2 and \#3 and (relative risk or hazard ratio) and } \\
\text { (incidence rate or prevalence or mortality) }\end{array}$ \\
\hline \#6 & Filters: English, Korean, Adult: 19+ years \\
\hline
\end{tabular}


Table 1. Cont.

\begin{tabular}{cc}
\hline Step & Search Strategy \\
\hline COPD & \\
$\# 3$ & chronic obstructive pulmonary disease or COPD \\
$\# 4$ & $\# 1$ and \#2 and \#3 \\
$\# 5$ & $\# 1$ and \#2 and \#3 and (relative risk or hazard ratio) and \\
$\# 6$ & (incidence rate or prevalence or mortality) \\
\hline
\end{tabular}

COPD, chronic obstructive pulmonary disease.

Only direct medical costs were included, and non-medical costs such as transportation cost or lost productivity cost were excluded. Domestic studies were preferentially searched since the treatment costs vary by country. Each cost was adjusted by the medical care component of the Consumer Price Index (CPI) in Korea using the equation below [32]. The adjusted costs were then transferred to 2020 US dollars [33].

$$
\text { Costs }_{\text {Current year }}=\text { Costs }_{\text {Base year }} \times \frac{C P I_{\text {Current year }}}{C P I_{\text {Base year }}}
$$

QALY was chosen as a tool to quantify the impact of $\mathrm{PM}_{2.5}$ exposure on health-related quality of life. The utilities of respective health states were obtained through literature search. The baseline utilities of age and sex-specific Korean general population were sourced from Korea National Health and Nutrition Examination Survey [34]. The utilities of event-free women of standard and increased exposure group were assumed to be the same, which is a conservative assumption.

\subsection{Sensitivity Analysis}

Univariate and probabilistic sensitivity analyses were performed to investigate the robustness of the model because our study was based on several assumptions. Univariate sensitivity analysis was conducted on discount rate $(0 \%, 3 \%, 7 \%)$, time horizon $(5,10,20$, 40 years), and relative risks (95\% confidence interval). For the probabilistic sensitivity analysis (PSA), 10,000 times of second-order Monte Carlo simulations were conducted on the relative risks, utilities, and costs. We applied a lognormal distribution for relative risks, a beta distribution for utilities, and a gamma distribution for costs, with the reference of previous studies. The applied distribution for each variable is presented in Table 2 . The PSA result was visualized by a scatterplot.

Table 2. Distribution of variables for probabilistic sensitivity analysis.

\begin{tabular}{cc}
\hline Variables & Distribution \\
\hline Relative risks & Lognormal \\
Lung cancer incidence & Lognormal \\
Lung cancer mortality & Lognormal \\
MI incidence & Lognormal \\
MI mortality & Lognormal \\
Stroke incidence & Lognormal \\
Stroke mortality & Lognormal \\
COPD incidence & Lognormal \\
COPD mortality & \\
\hline
\end{tabular}


Table 2. Cont.

\begin{tabular}{cc}
\hline Variables & Distribution \\
\hline Utilities & Beta \\
Lung cancer, first year & Beta \\
Lung cancer, second year & Beta \\
MI & Beta \\
Post MI & Beta \\
Stroke & Beta \\
Post stroke & Beta \\
COPD &
\end{tabular}

\begin{tabular}{ll}
\hline & Health care costs \\
Lung cancer, first year & Gamma \\
Lung cancer, second year & Gamma \\
Lung cancer death & Gamma \\
Non-fatal MI & Gamma \\
Post MI & Gamma \\
CHD death & Gamma \\
Non-fatal stroke & Gamma \\
Post stroke & Gamma \\
CVD death & Gamma \\
COPD & Gamma \\
COPD death & Gamma \\
\hline CHD, coronary heart disease; CVD, cardiovascular disease; MI, myocardial infarction; COPD, chronic obstructive \\
pulmonary disease.
\end{tabular}

\section{Results}

\subsection{Input Data}

For the relative risks, eight studies were selected through systematic review [29,30,35-40]. Relative risk data from the eight studies applied in our model and each reference are shown in Table 3. Among the eight studies, two of them were meta-analysis studies and six were cohort studies. The study populations were from the US, Canada, Europe, South America, and Taiwan. The sizes of the study cohorts were from 65,893 to 367,383 and the follow-up period was from 6 to 14 years. The incremental $\mathrm{PM}_{2.5}$ concentration was $10 \mu \mathrm{g} / \mathrm{m}^{3}$ in five studies and $5 \mu \mathrm{g} / \mathrm{m}^{3}$ in three studies. Because the data that matched the characteristics of our target population were not available from domestic studies, relative risks were sourced from international studies. Incidence and mortality rates for each disease were sourced from Korea Statistics. The annual incidence rates, mortality rates, and relative risks used in the model are summarized in Table 3.

Table 3. Annual incidence and mortality rates for each disease states and the relative risks related to $\mathrm{PM}_{2.5}$ exposure used in the model.

\begin{tabular}{ccccccc}
\hline Disease & Age & & Ref & Relative Risk & Ref \\
\hline \multirow{4}{*}{ Lung cancer } & Incidence rate & $50-49$ & 0.0001 & & & \\
& & $60-69$ & 0.0003 & {$[34]$} & $1.42(1.02-1.98)$ & {$[37]$} \\
& & $70-$ & 0.0014 & & & \\
\cline { 2 - 7 } & Mortality rate & - & 0.2109 & {$[41]$} & $1.27(1.03-1.56)$ & {$[40]$} \\
\hline
\end{tabular}


Table 3. Cont.

\begin{tabular}{|c|c|c|c|c|c|c|}
\hline Disease & & Age & & Ref & Relative Risk & Ref \\
\hline \multirow{10}{*}{$\begin{array}{l}\text { Myocardial } \\
\text { infarction }\end{array}$} & \multirow{5}{*}{ Incidence rate } & 45 & 0.0004 & \multirow{5}{*}{ [42] } & \multirow{5}{*}{$1.22(1.04-1.44)$} & \multirow{5}{*}{ [36] } \\
\hline & & 55 & 0.0013 & & & \\
\hline & & 65 & 0.0033 & & & \\
\hline & & 75 & 0.006 & & & \\
\hline & & 85 & 0.0085 & & & \\
\hline & \multirow{5}{*}{ Mortality rate } & 45 & 0.0168 & \multirow{5}{*}{ [42] } & \multirow{5}{*}{$1.20(1.02-1.41)$} & \multirow{5}{*}{ [29] } \\
\hline & & 55 & 0.0324 & & & \\
\hline & & 65 & 0.0618 & & & \\
\hline & & 75 & 0.1152 & & & \\
\hline & & 85 & 0.2076 & & & \\
\hline \multirow{10}{*}{ Stroke } & \multirow{5}{*}{ Incidence rate } & 45 & 0.0011 & \multirow{5}{*}{ [42] } & \multirow{5}{*}{$1.28(1.02-1.61)$} & \multirow{5}{*}{ [30] } \\
\hline & & 55 & 0.0029 & & & \\
\hline & & 65 & 0.0076 & & & \\
\hline & & 75 & 0.0158 & & & \\
\hline & & 85 & 0.025 & & & \\
\hline & \multirow{5}{*}{ Mortality rate } & 45 & 0.0046 & \multirow{5}{*}{ [42] } & \multirow{5}{*}{$1.34(0.94-1.91)$} & \multirow{5}{*}{ [35] } \\
\hline & & 55 & 0.0112 & & & \\
\hline & & 65 & 0.0263 & & & \\
\hline & & 75 & 0.0604 & & & \\
\hline & & 85 & 0.1295 & & & \\
\hline \multirow{6}{*}{ COPD } & \multirow{4}{*}{ Incidence rate } & $40-49$ & 0.008 & \multirow{4}{*}[34]{} & \multirow{4}{*}{$1.08(1.04-1.11)$} & \multirow{4}{*}{ [38] } \\
\hline & & $50-59$ & 0.024 & & & \\
\hline & & $60-69$ & 0.114 & & & \\
\hline & & $70-$ & 0.136 & & & \\
\hline & \multirow{2}{*}{ Mortality rate } & 75 & 0.0002 & \multirow{2}{*}{ [41] } & 1.169 & \multirow{2}{*}{ [39] } \\
\hline & & 85 & 0.0009 & & (1.136-1.203) & \\
\hline
\end{tabular}

COPD, chronic obstructive pulmonary disease; Ref, reference.

Annual costs and QALY data applied for the model and their references are summarized in Table 4. The costs for each health states were referred from domestic studies including cost data estimated from the Korean National Health Insurance database. The age and sex-specific EQ-5D of the general Korean population was sourced from Korea National Health and Nutrition examination survey (2015) [34].

Table 4. Annual costs (per person) and utility used in the model.

\begin{tabular}{ccccc}
\hline State & $\begin{array}{c}\text { Cost, Year 2020 } \\
\text { (USD) }\end{array}$ & Ref & Utility & Ref \\
\hline Lung cancer, first year & 19,495 & {$[25]$} & 0.61 & {$[43]$} \\
Lung cancer, second year & 6180 & {$[25]$} & 0.50 & {$[43]$} \\
Lung cancer death & 17,089 & {$[44]$} & - & \\
Non-fatal MI & 7026 & {$[45]$} & 0.71 & {$[46]$} \\
Post MI & 1156 & {$[45]$} & 0.75 & {$[46]$} \\
CHD death & 1494 & {$[45]$} & - & \\
Non-fatal stroke & 7260 & {$[45]$} & 0.63 & {$[47]$} \\
Post stroke & 941 & {$[45]$} & 0.72 & {$[47]$} \\
CVD death & 2062 & {$[45]$} & - & \\
COPD & 809 & {$[24]$} & 0.8 & {$[48]$} \\
COPD death & 2577 & {$[24]$} & - & \\
\hline
\end{tabular}

$\overline{\mathrm{CHD}}$, coronary heart disease; CVD, cardiovascular disease; MI, myocardial infarction; COPD, chronic obstructive pulmonary disease; Ref, reference.

\subsection{Base-Case Analysis}

The model estimated that the increased exposure to $\mathrm{PM}_{2.5}$ would cost USD 9309 per woman for lifetime healthcare, whereas the lifetime healthcare cost would be USD 8367 per 
woman when exposed to the standard $\mathrm{PM}_{2.5}$ concentration. The predicted QALYs were 32.08 and 30.64 for increased exposure and standard exposure, respectively (Figure 2). The lifetime healthcare cost increased by $11.3 \%$ and QALYs decreased by $4.5 \%$ in the case of increased exposure to $\mathrm{PM}_{2.5}$.

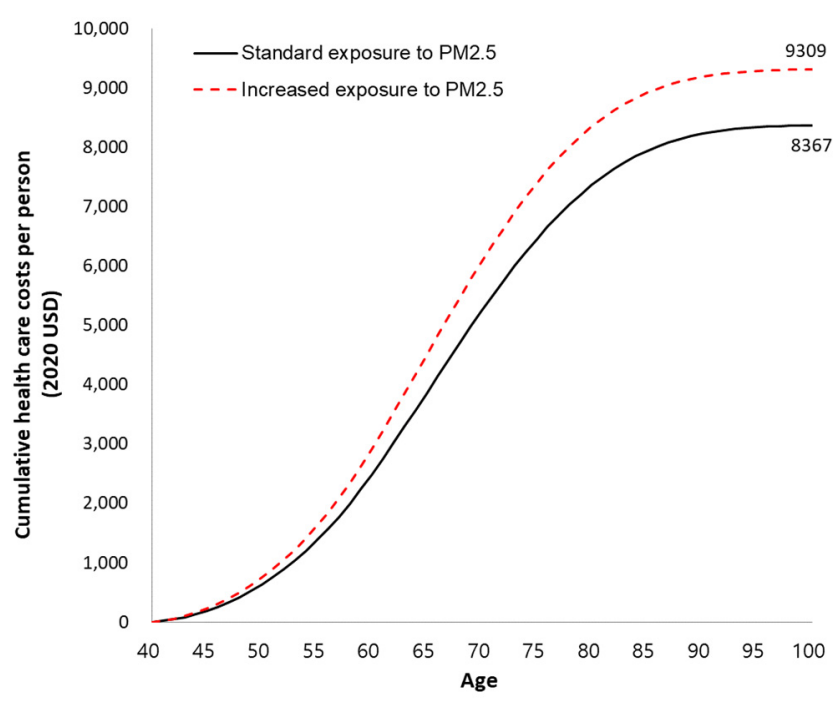

(a)

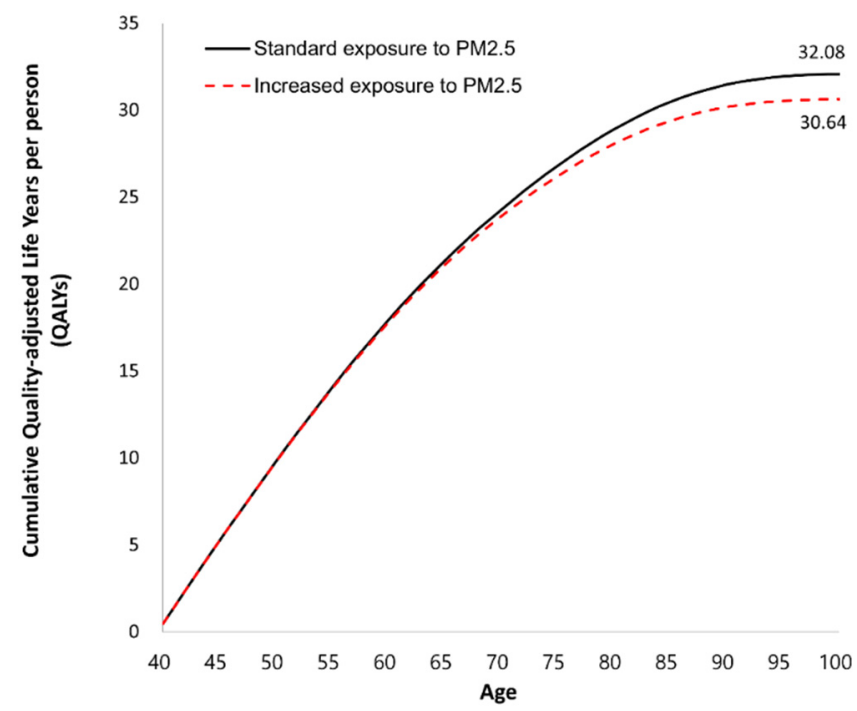

(b)

Figure 2. Cumulative lifetime healthcare costs and quality-adjusted life years for Korean adult women who were exposed to either increased or standard concentration of $\mathrm{PM}_{2.5}$. (a) Lifetime healthcare costs; (b) quality-adjusted life years.

\subsection{One-Way Sensitivity Analysis}

The results of one-way sensitivity analysis are summarized in Table 5. The one-way sensitivity analysis demonstrated that exposure to an increased concentration of $\mathrm{PM}_{2.5}$ generally shows higher healthcare costs and lower QALYs compared to the standard exposure group across various assumptions. Specifically, when the relative risk of lung cancer incidence was varied, the negative impact of the increased exposure to $\mathrm{PM}_{2.5}$ was the highest resulting in a $23 \%$ increase in lifetime healthcare cost. When the discount rate was changed by $0 \%, 3 \%$, and 7\%, the costs were USD 38,589, USD 15,753, and USD 5800 at the increased exposure, which were $7.2 \%, 9.8 \%$, and $12.6 \%$ increases compared to the cost of standard exposure, respectively. As the time horizon increased, the direct healthcare costs of $\mathrm{PM}_{2.5}$ exposure escalated from USD 189 for 5 years to USD 8254 for 40 years. This indicates that the negative economic impact associated with $\mathrm{PM}_{2.5}$ exposure increased over time, and Figure 2 also suggests that the negative impact accelerates as time progresses.

Table 5. One-way sensitivity analyses for Korean adult women who are exposed to increased concentration of ambient PM2.5 compared with women exposed to standard concentration.

\begin{tabular}{|c|c|c|c|c|c|c|c|}
\hline Parameters & $\begin{array}{c}\mathrm{PM}_{2.5} \\
\text { Exposure }\end{array}$ & $\begin{array}{l}\text { Cost } \\
\text { (USD) }\end{array}$ & QALYs & $\begin{array}{l}\text { Incremental } \\
\text { Cost (USD) }\end{array}$ & $\begin{array}{l}\text { Difference } \\
(\%)\end{array}$ & $\begin{array}{c}\text { Incremental } \\
\text { QALYs }\end{array}$ & $\begin{array}{c}\text { Difference } \\
(\%)\end{array}$ \\
\hline \multicolumn{8}{|l|}{ Discount rate $(\%)$} \\
\hline \multirow{2}{*}{0} & Standard & 36,013 & 32.08 & & & & \\
\hline & Increased & 38,589 & 30.64 & 2575 & $7.2 \%$ & -1.44 & $-4.5 \%$ \\
\hline \multirow{2}{*}{3} & Standard & 14,353 & - & & & & \\
\hline & Increased & 15,753 & - & 1400 & $9.8 \%$ & -0.51 & $-2.7 \%$ \\
\hline \multirow[b]{2}{*}{5} & Standard & 8367 & - & & & & \\
\hline & Increased & 9309 & - & 942 & $11.3 \%$ & -0.28 & $-1.9 \%$ \\
\hline \multirow[b]{2}{*}{7} & Standard & 5152 & - & & & & \\
\hline & Increased & 5800 & - & 648 & $12.6 \%$ & -0.16 & $-1.4 \%$ \\
\hline
\end{tabular}


Table 5. Cont

\begin{tabular}{|c|c|c|c|c|c|c|c|}
\hline Parameters & $\begin{array}{c}\mathrm{PM}_{2.5} \\
\text { Exposure }\end{array}$ & $\begin{array}{l}\text { Cost } \\
\text { (USD) }\end{array}$ & QALYs & $\begin{array}{l}\text { Incremental } \\
\text { Cost (USD) }\end{array}$ & $\begin{array}{c}\text { Difference } \\
(\%)\end{array}$ & $\begin{array}{c}\text { Incremental } \\
\text { QALYs }\end{array}$ & $\begin{array}{c}\text { Difference } \\
(\%)\end{array}$ \\
\hline \multicolumn{8}{|l|}{ Time horizon (years) } \\
\hline \multirow{2}{*}{5} & Standard & 158 & 4.75 & & & & \\
\hline & Increased & 189 & 4.74 & 31 & $20.0 \%$ & 0.00 & $-0.1 \%$ \\
\hline \multirow{2}{*}{10} & Standard & 573 & 9.31 & & & & \\
\hline & Increased & 679 & 9.29 & 106 & $18.5 \%$ & -0.02 & $-0.2 \%$ \\
\hline \multirow{2}{*}{20} & Standard & 2349 & 17.55 & & & & \\
\hline & Increased & 2751 & 17.43 & 402 & $17.1 \%$ & -0.12 & $-0.7 \%$ \\
\hline \multirow[b]{2}{*}{40} & Standard & 7274 & 28.70 & & & & \\
\hline & Increased & 8254 & 27.89 & 980 & $13.5 \%$ & -0.81 & $-2.8 \%$ \\
\hline \multicolumn{8}{|c|}{ Relative risk for Lung Cancer incidence } \\
\hline \multirow{4}{*}{$\begin{array}{c}\text { Lower bound of } \\
95 \% \text { CI } \\
\text { Upper bound of } \\
95 \% \text { CI }\end{array}$} & Standard & 8367 & 32.08 & & & & \\
\hline & Increased & 8515 & 31.57 & 148 & $1.76 \%$ & -0.52 & $-1.61 \%$ \\
\hline & Standard & 8367 & 32.08 & & & & \\
\hline & Increased & 10,264 & 29.52 & 1897 & $22.68 \%$ & -2.56 & $-7.97 \%$ \\
\hline \multicolumn{8}{|c|}{ Relative risk for Lung Cancer mortality } \\
\hline \multirow{4}{*}{$\begin{array}{c}\text { Lower bound of } \\
95 \% \text { CI } \\
\text { Upper bound of } \\
95 \% \text { CI }\end{array}$} & Standard & 8367 & 32.08 & & & & \\
\hline & Increased & 9553 & 30.77 & 1186 & $14.18 \%$ & -1.31 & $-4.09 \%$ \\
\hline & Standard & 8367 & 32.08 & & & & \\
\hline & Increased & 9093 & 30.53 & 726 & $8.68 \%$ & -1.55 & $-4.84 \%$ \\
\hline \multicolumn{8}{|c|}{ Relative risk for Myocardial Infarction incidence } \\
\hline \multirow{4}{*}{$\begin{array}{l}\text { Lower bound of } \\
95 \% \text { CI } \\
\text { Upper bound of } \\
95 \% \text { CI }\end{array}$} & Standard & 8367 & 32.08 & & & & \\
\hline & Increased & 9287 & 30.66 & 920 & $11.00 \%$ & -1.42 & $-4.42 \%$ \\
\hline & Standard & 8367 & 32.08 & & & & \\
\hline & Increased & 9338 & 30.62 & 971 & $11.60 \%$ & -1.47 & $-4.57 \%$ \\
\hline \multicolumn{8}{|c|}{ Relative risk for Myocardial Infarction mortality } \\
\hline \multirow{4}{*}{$\begin{array}{c}\text { Lower bound of } \\
95 \% \text { CI } \\
\text { Upper bound of } \\
95 \% \text { CI }\end{array}$} & Standard & 8367 & 32.08 & & & & \\
\hline & Increased & 9318 & 30.67 & 951 & $11.37 \%$ & -1.41 & $-4.41 \%$ \\
\hline & Standard & 8367 & 32.08 & & & & \\
\hline & Increased & 9301 & 30.62 & 934 & $11.16 \%$ & -1.46 & $-4.56 \%$ \\
\hline \multicolumn{8}{|c|}{ Relative risk for Stroke incidence } \\
\hline \multirow{4}{*}{$\begin{array}{c}\text { Lower bound of } \\
95 \% \text { CI } \\
\text { Upper bound of } \\
95 \% \text { CI }\end{array}$} & Standard & 8367 & 32.08 & & & & \\
\hline & Increased & 9240 & 30.71 & 873 & $10.43 \%$ & -1.37 & $-4.28 \%$ \\
\hline & Standard & 8367 & 32.08 & & & & \\
\hline & Increased & 9405 & 30.56 & 1038 & $12.40 \%$ & -1.52 & $-4.75 \%$ \\
\hline \multicolumn{8}{|c|}{ Relative risk for Stroke mortality } \\
\hline \multirow{4}{*}{$\begin{array}{l}\text { Lower bound of } \\
95 \% \text { CI } \\
\text { Upper bound of } \\
95 \% \text { CI }\end{array}$} & Standard & 8367 & 32.08 & & & & \\
\hline & Increased & 9337 & 30.74 & 970 & $11.60 \%$ & -1.34 & $-4.17 \%$ \\
\hline & Standard & 8367 & 32.08 & & & & \\
\hline & Increased & 9272 & 30.51 & 905 & $10.82 \%$ & -1.57 & $-4.89 \%$ \\
\hline \multicolumn{8}{|c|}{ Relative risk for COPD incidence } \\
\hline \multirow{4}{*}{$\begin{array}{c}\text { Lower bound of } \\
95 \% \text { CI } \\
\text { Upper bound of } \\
95 \% \text { CI }\end{array}$} & Standard & 8367 & 32.08 & & & & \\
\hline & Increased & 9193 & 30.71 & 826 & $9.88 \%$ & -1.37 & $-4.27 \%$ \\
\hline & Standard & 8367 & 32.08 & & & & \\
\hline & Increased & 9393 & 30.59 & 1026 & $12.27 \%$ & -1.49 & $-4.64 \%$ \\
\hline \multicolumn{8}{|c|}{ Relative risk for COPD mortality } \\
\hline & Standard & 8367 & 32.08 & & & & \\
\hline $95 \%$ CI & Increased & 9309 & 30.64 & 942 & $11.26 \%$ & -1.44 & $-4.48 \%$ \\
\hline Upper bound of & Standard & 8367 & 32.08 & & & & \\
\hline $95 \%$ CI & Increased & 9310 & 30.64 & 943 & $11.27 \%$ & -1.44 & $-4.49 \%$ \\
\hline
\end{tabular}




\subsection{Probabilistic Sensitivity Analysis}

Probabilistic sensitivity analysis showed that the costs of the increased concentration group varied from USD 5570 to USD 14,045 (134.6\%), while the costs of the standard concentration group varied from USD 5382 to USD 12,628 (152.1\%). However, the variation for QALYs was smaller (81.7\% vs. $88.4 \%$ ) between the two groups (Table 6). The result of the probabilistic sensitivity analysis is visualized in Figure 3.

Table 6. Summary of the probabilistic sensitivity analyses results.

\begin{tabular}{ccccc}
\hline & \multicolumn{2}{c}{ Costs (USD) } & \multicolumn{2}{c}{ QALYs } \\
\cline { 2 - 5 } Statistic & $\begin{array}{c}\text { Increased } \\
\text { Exposure to } \\
\mathbf{P M}_{\mathbf{2 . 5}}\end{array}$ & $\begin{array}{c}\text { Standard } \\
\text { Exposure to } \\
\mathbf{P M}_{\mathbf{2 . 5}}\end{array}$ & $\begin{array}{c}\text { Increased } \\
\text { Exposure to }\end{array}$ & $\begin{array}{c}\text { Standard } \\
\text { Exposure to } \\
\text { PM }_{\mathbf{2 . 5}}\end{array}$ \\
\hline Mean & 9352 & 8367 & 30.59 & 32.05 \\
Std Deviation & 1064 & 928 & 2.74 & 2.89 \\
Minimum & 5570 & 5382 & 18.78 & 19.75 \\
2.50\% & 7410 & 6682 & 23.91 & 24.96 \\
10\% & 8020 & 7201 & 26.65 & 27.83 \\
Median & 9304 & 8322 & 31.20 & 32.79 \\
90\% & 10,743 & 9587 & 33.54 & 35.07 \\
97.50\% & 11,583 & 10,316 & 34.20 & 35.46 \\
Maximum & 14,045 & 12,628 & 35.39 & 35.88 \\
\hline
\end{tabular}

QALYs, quality-adjusted life years.

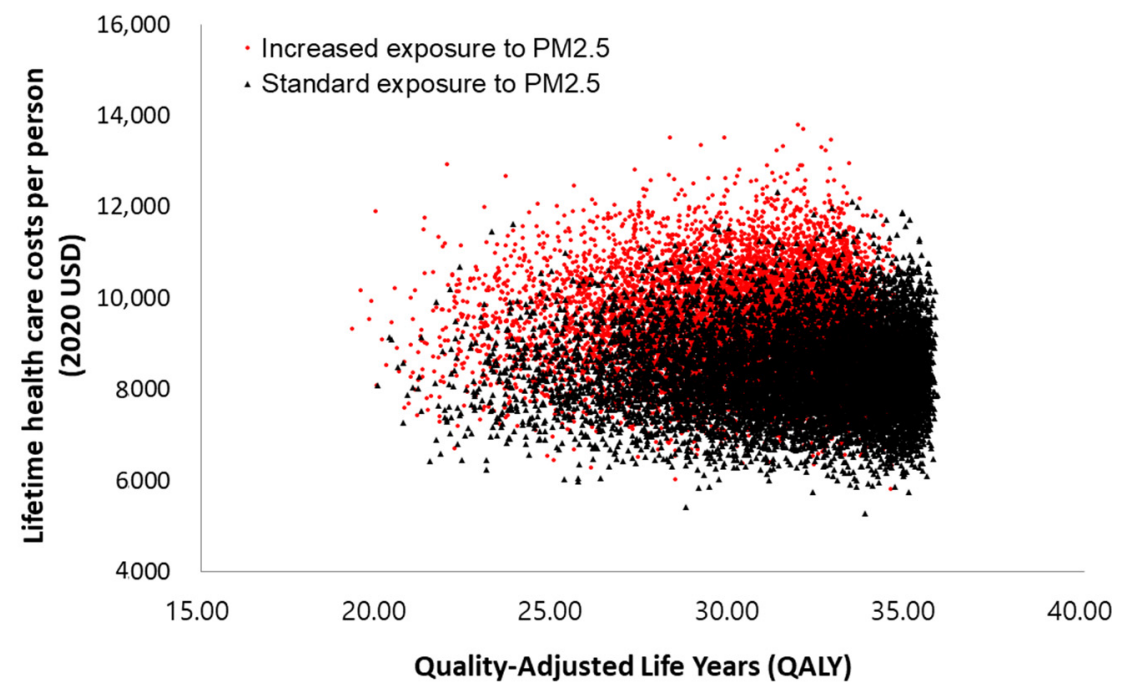

Figure 3. Scatter plot of the probabilistic sensitivity analyses results.

\subsection{Model Validation}

External validation was performed to compare our result to actual observed epidemiological mortality data. In our study, we compared the lung cancer mortality projection result with the observed data reported by Li et al. [21]. The study involved a cohort of 118,551 final participants, $58.9 \%$ of which were women, and the follow-up period was 15 years. The cohort was exposed to $31-54 \mu \mathrm{g} / \mathrm{m}^{3}$ of $\mathrm{PM}_{2.5}$. For direct comparison, the analysis period of our Markov model was set to 15 cycles. Li and colleagues reported 77.34 lung cancer deaths per 100,000 persons per year for a $\mathrm{PM}_{2.5}$ exposed condition, which was higher than our study projection (56.07 lung cancer deaths per 100,000 persons per year (Table 7)) yet understandable, given the difference in the $\mathrm{PM}_{2.5}$ exposure. 
Table 7. Result of the model validation analysis.

\begin{tabular}{ccc}
\hline & \multicolumn{2}{c}{ Lung Cancer Mortality (Case/Person per Year) } \\
\cline { 2 - 3 } & Li et al. (2020) & Model \\
\hline Increased exposure to $\mathrm{PM}_{2.5}$ & 0.007734 & 0.005607 \\
\hline
\end{tabular}

\section{Discussion}

Our model estimated that adult Korean women exposed to an increased concentration of $\mathrm{PM}_{2.5}$ incurred an additional USD 942 in their lifetime and lived 1.44 QALYs shorter compared to the standard exposure group. The one-way sensitivity analysis showed that higher healthcare costs and shorter QALYs were expected for the increased exposure group, regardless of various assumptions. For model validation, the results were compared with the external literature, which studied the relative risk of lung cancer death due to $\mathrm{PM}_{2.5}$ exposure. The predicted mortality rate from our model was 0.005607 , which was slightly lower than the observed mortality rate of 0.007734 reported by Li et al. (2020) [21] However, this difference can be explained by the fact that the mortality rate due to lung cancer in China is higher than in South Korea [49], and the study population of Li et al. (2020) was exposed to $31-54 \mu \mathrm{g} / \mathrm{m}^{3}$ of $\mathrm{PM}_{2.5}$, which is higher than $25 \mu \mathrm{g} / \mathrm{m}^{3}$, the exposure concentration of the hypothetical cohort in our model. For further validation, the incidence rate of stroke was compared to that of another study [50] where the observed incidence rate was 393 cases per 100,000 person years (0.03930). Our estimation (0.03011) was comparable to the value obtained from the observation data. Therefore, we concluded that our model is valid, and the result of our model is acceptable. Though the data are not shown, we estimated life year expectancy of each cohort by rewarding each cycle being 1 without adjusting the quality of life. When the disease burden was not considered, the expected life years of 40-year-old Korean women were 39.47 years and 41.34 years for increased exposure and standard exposure, respectively. The life expectancy of 40-year-old Korean women was 47.3 years in 2020, based on the lifetable reported by Statistics Korea [51]. This shows that our study provides a conservative estimate.

The economic loss and health impact due to ambient particulate matters has been reported in several previous studies, yet our study is the first attempt to project the longterm effect by using a simulation model. While most studies reported the $\mathrm{PM}_{2.5}$-induced economic loss as a regional unit [12], Yin et al. (2017) reported that the $\mathrm{PM}_{2.5}$ concentration in Beijing $\left(40.26-92.30 \mu \mathrm{g} / \mathrm{m}^{3}\right)$ induces an economic loss of USD 18 to 147 per capita yearly [52]. These data were calculated by the Willingness to Pay (WTP) or Amended Human Capital (AHC) method, and they include the disutility of illness, productivity loss, medical expenditures associated with illnesses, and expenditures on disease prevention. Because the projection method used in our study and Yin et al.'s (2017) study is different in nature, it is not appropriate to directly compare the results between the two studies. The relatively low health cost in our study is due to not only the analysis method or exposure concentration difference but also the conservative assumptions defined in our model. In our model, we included four diseases in circulatory, respiratory, and neoplasm (lung cancer), which were known to be highly related to $\mathrm{PM}_{2.5}$ exposure. However, Yin et al.'s (2017) study included additional endocrine/nutritional/metabolic diseases, mental and behavioral disorders, and nervous system diseases and this could increase the cost.

The Markov model method was used in our study to extrapolate the lifetime effect of $\mathrm{PM}_{2.5}$ based on the data adopted from the existing literature, such as transition probabilities between health states. However, because of this, there are some methodological limitations in our study. First, the relative risks for the diseases used in our model were derived from international studies. The systematic review by Lim et al. (2020) reported the hazard ratios for mortalities due to $\mathrm{PM}_{2.5}$ increase in the Korean population [53]. However, this study was conducted targeting only the elderly population and could not represent the mortality of middle-aged Korean women. Kim et al. (2018) studied 570 thousand deaths across three metropolitan cities in Korea and reported that $\mathrm{PM}_{2.5}$ is significantly associated with daily 
mortality of all causes, and respiratory and cardiovascular diseases [54]. According to the study, the estimation can be updated when the relative risks of the domestic population suitable for our model is reported. Secondly, the effect of $\mathrm{PM}_{2.5}$ on the economic cost and health outcomes may have been underestimated since only four diseases were included in the model. There is gaining evidence in the relationship between fine particulate matter exposure and various diseases. Some studies have reported that exposure to $\mathrm{PM}_{2.5}$ is related to the increased morbidity of asthma attacks, diabetes, obesity, Alzheimer's, Parkinson's, dementia, mild cognitive disorders, and bladder cancer [52,55], yet the clinical relevance is inconsistent [1] and further study is needed. In addition, we assumed that the relative risks were constant regardless of the exposure period, which is a clear limitation. However, the effect of $\mathrm{PM}_{2.5}$ is likely to accumulate for prolonged exposure [56,57]. Finally, although we focused on the effect of $\mathrm{PM}_{2.5}$ in this study, there are various environmental factors that we did not put into the model, such as toxic elements and possible medicinal interference during the cycles, since the quantified impact (such as relative risks) was either not available or not statistically significant [58,59]. Despite those limitations, our study is the first attempt to project the economic and quality of life impact of $\mathrm{PM}_{2.5}$ exposure based on a simulation model, which could eliminate the effect of variables other than the exposure to PM2.5 itself.

\title{
5. Conclusions
}

The negative impact of $\mathrm{PM}_{2.5}$ was higher on the healthcare costs than on the QALYs, and accelerated as the exposure time accumulated. The results were consistent across various assumptions. A prompt, aggressive intervention is needed to reduce burdens associated with $\mathrm{PM}_{2.5}$ exposure.

Supplementary Materials: The following are available online at https:/ / www.mdpi.com/article/10 .3390/ijerph19052494/s1, Supplementary File: Study selection process.

Author Contributions: Conceptualization, G.S. and S.B.; methodology, G.C., Y.K., and S.B.; software, G.C..; validation, S.B. and G.S.; formal analysis, G.C.; investigation, G.C and S.B.; resources, G.C. and Y.K.; data curation, G.C.; writing-original draft preparation, G.C.; writing-review and editing, G.S. and S.B.; visualization, G.C.; supervision, S.B.; project administration, S.B. All authors have read and agreed to the published version of the manuscript.

Funding: This research was supported by the National Research Foundation NRF-2021R1F1A1050281.

Institutional Review Board Statement: Not applicable.

Informed Consent Statement: Not applicable.

Data Availability Statement: The data presented in this study are available in the Supplementary Materials.

Conflicts of Interest: The authors declare no conflict of interest.

\begin{abstract}
Abbreviations
AQGs, air quality guidelines; CHD, coronary heart disease; COPD, chronic obstructive pulmonary disease; CPI, consumer price index; CVD, cardiovascular disease; EPA, environmental protection agency; IT, interim target-3; MI, myocardial infarction; Ref, reference; PM2.5, particulate matter (particle size $<2.5 \mu \mathrm{m}$ ); PICO, population intervention comparison outcomes; QALYs, qualityadjusted life years; WHO, World Health Organization.
\end{abstract}

\section{References}

1. Ambient Air Pollution: A Global Assessment of Exposure and Burden of Disease; World Health Organization: Geneva, Switzerland, 2016.

2. Rojas-Rueda, D.; Alsufyani, W.; Herbst, C.; AlBalawi, S.; Alsukait, R.; Alomran, M. Ambient particulate matter burden of disease in the Kingdom of Saudi Arabia. Environ. Res. 2021, 197, 111036. [CrossRef] [PubMed] 
3. Kim, K.H.; Kabir, E.; Kabir, S. A review on the human health impact of airborne particulate matter. Environ. Int. 2015, 74, 136-143. [CrossRef] [PubMed]

4. Burden of Disease from Ambient Air Pollution for 2012; World Health Organization: Geneva, Switzerland, 2014.

5. $\quad$ Air Quality Guideline Global Update 2005; World Health Organization: Geneva, Switzerland, 2005.

6. Concentration of Fine Particulate Matter in 2020; Ministry of Envrironment: Sejong, Korea, 2021. Available online: https:/ /apps. who.int/iris/handle/10665/250141 (accessed on 14 August 2021).

7. Lee, D.; Choi, J.-Y.; Myoung, J.; Kim, O.; Park, J.; Shin, H.-J.; Ban, S.-J.; Park, H.-J.; Nam, K.-P. Analysis of a Severe PM2.5 Episode in the Seoul Metropolitan Area in South Korea from 27 February to 7 March 2019: Focused on Estimation of Domestic and Foreign Contribution. Atmosphere 2019, 10, 756. [CrossRef]

8. Cohen, A.J.; Brauer, M.; Burnett, R.; Anderson, H.R.; Frostad, J.; Estep, K.; Balakrishnan, K.; Brunekreef, B.; Dandona, L.; Dandona, R.; et al. Estimates and 25-year trends of the global burden of disease attributable to ambient air pollution: An analysis of data from the Global Burden of Diseases Study 2015. Lancet 2017, 389, 1907-1918. [CrossRef]

9. Jaganathan, S.; Jaacks, L.M.; Magsumbol, M.; Walia, G.K.; Sieber, N.L.; Shivasankar, R.; Dhillon, P.K.; Hameed, S.S.; Schwartz, J.; Prabhakaran, D. Association of Long-Term Exposure to Fine Particulate Matter and Cardio-Metabolic Diseases in Low- and Middle-Income Countries: A Systematic Review. Int. J. Environ. Res. Public Health 2019, 16, 2541. [CrossRef] [PubMed]

10. Ni, L.; Chuang, C.-C.; Zuo, L. Fine particulate matter in acute exacerbation of COPD. Front. Physiol. 2015, 6, 294. [CrossRef]

11. Pelucchi, C.; Negri, E.; Gallus, S.; Boffetta, P.; Tramacere, I.; La Vecchia, C. Long-term particulate matter exposure and mortality: A review of European epidemiological studies. BMC Public Health 2009, 9, 453. [CrossRef]

12. Zhang, M.; Song, Y.; Cai, X.; Zhou, J. Economic assessment of the health effects related to particulate matter pollution in 111 Chinese cities by using economic burden of disease analysis. J. Environ. Manag. 2008, 88, 947-954. [CrossRef]

13. Hwang, I.; Kim, C.; Son, W. Benefits of Management Policy of Seoul on Airborne Particulate Matter; The Seoul Institute: Seoul, Korea, 2019.

14. Correia, A.W.; Pope, C.A., 3rd; Dockery, D.W.; Wang, Y.; Ezzati, M.; Dominici, F. Effect of air pollution control on life expectancy in the United States: An analysis of 545 U.S. counties for the period from 2000 to 2007. Epidemiology 2013, 24, 23-31. [CrossRef]

15. Liu, C.; Chen, R.; Sera, F.; Vicedo-Cabrera, A.M.; Guo, Y.; Tong, S.; Coelho, M.; Saldiva, P.H.N.; Lavigne, E.; Matus, P.; et al. Ambient Particulate Air Pollution and Daily Mortality in 652 Cities. N. Engl. J. Med. 2019, 381, 705-715. [CrossRef]

16. Stanaway, J.D.; Afshin, A.; Gakidou, E.; Lim, S.S.; Abate, D.; Abate, K.H.; Abbafati, C.; Abbasi, N.; Abbastabar, H.; Abd-Allah, F.; et al. Global, regional, and national comparative risk assessment of 84 behavioural, environmental and occupational, and metabolic risks or clusters of risks for 195 countries and territories, 1990-2017: A systematic analysis for the Global Burden of Disease Study 2017. Lancet 2018, 392, 1923-1994.

17. Lee, J.; Han, A.R.; Choi, D.; Lim, K.M.; Bae, S. Modeling lifetime costs and health outcomes attributable to secondhand smoke exposure at home among Korean adult women. BMJ Open 2017, 7, e013292. [CrossRef] [PubMed]

18. Briggs, A.; Sculpher, M. An introduction to Markov modelling for economic evaluation. Pharmacoeconomics 1998, 13, 397-409. [CrossRef] [PubMed]

19. Sonnenberg, F.A.; Beck, J.R. Markov models in medical decision making: A practical guide. Med. Decis. Mak. 1993, 13, 322-338. [CrossRef] [PubMed]

20. Hamra, G.B.; Guha, N.; Cohen, A.; Laden, F.; Raaschou-Nielsen, O.; Samet, J.M.; Vineis, P.; Forastiere, F.; Saldiva, P.; Yorifuji, T.; et al. Outdoor particulate matter exposure and lung cancer: A systematic review and meta-analysis. Environ. Health Perspect. 2014, 122, 906-911. [CrossRef]

21. Li, J.; Lu, X.; Liu, F.; Liang, F.; Huang, K.; Yang, X.; Xiao, Q.; Chen, J.; Liu, X.; Cao, J.; et al. Chronic Effects of High Fine Particulate Matter Exposure on Lung Cancer in China. Am. J. Respir. Crit. Care Med. 2020, 202, 1551-1559. [CrossRef]

22. Wang, Y.; Eliot, M.N.; Wellenius, G.A. Short-term changes in ambient particulate matter and risk of stroke: A systematic review and meta-analysis. J. Am. Heart Assoc. 2014, 3, e000983. [CrossRef]

23. Zhu, W.; Cai, J.; Hu, Y.; Zhang, H.; Han, X.; Zheng, H.; Wu, J. Long-term exposure to fine particulate matter relates with incident myocardial infarction (MI) risks and post-MI mortality: A meta-analysis. Chemosphere 2021, 267, 128903. [CrossRef]

24. Kim, J.; Rhee, C.K.; Yoo, K.H.; Kim, Y.S.; Lee, S.W.; Park, Y.B.; Lee, J.H.; Oh, Y.; Lee, S.D.; Kim, Y.; et al. The health care burden of high grade chronic obstructive pulmonary disease in Korea: Analysis of the Korean Health Insurance Review and Assessment Service data. Int. J. Chronic Obstr. Pulm. Dis. 2013, 8, 561.

25. Kim, S.Y.; Kim, S.G.; Park, J.H.; Park, E.C. Costs of initial cancer care and its affecting factors. J. Prev. Med. Public Health 2009, 42, 243-250. [CrossRef]

26. Ward, S.; Jones, M.L.; Pandor, A.; Holmes, M.; Ara, R.; Ryan, A.; Yeo, W.; Payne, N. A systematic review and economic evaluation of statins for the prevention of coronary events. Health Technol. Assess. 2017, 11, 1-160. [CrossRef] [PubMed]

27. Bae, S.; Lee, S.; Bae, E.Y.; Jang, S. Korean guidelines for pharmacoeconomic evaluation (second and updated version): Consensus and compromise. Pharmacoeconomics 2013, 31, 257-267. [CrossRef] [PubMed]

28. Weinstein, M.C. Recommendations of the Panel on Cost-Effectiveness in Health and Medicine. JAMA J. Am. Med. Assoc. 1996, 276, 1253-1258. [CrossRef]

29. Lipsett, M.J.; Ostro, B.D.; Reynolds, P.; Goldberg, D.; Hertz, A.; Jerrett, M.; Smith, D.F.; Garcia, C.; Chang, E.T.; Bernstein, L. Long-term exposure to air pollution and cardiorespiratory disease in the California teachers study cohort. Am. J. Respir. Crit. Care Med. 2011, 184, 828-835. [CrossRef] 
30. Miller, K.A.; Siscovick, D.S.; Sheppard, L.; Shepherd, K.; Sullivan, J.H.; Anderson, G.L.; Kaufman, J.D. Long-Term Exposure to Air Pollution and Incidence of Cardiovascular Events in Women. N. Engl. J. Med. 2007, 356, 447-458. [CrossRef]

31. Higgins, J.P.; Thomas, J.; Chandler, J.; Cumpston, M.; Li, T.; Page, M.J.; Welch, V.A. Cochrane Handbook for Systematic Reviews of Interventions; John Wiley \& Sons: Hoboken, NJ, USA, 2019.

32. Consumer Price Index. Available online: https://kosis.kr/statHtml/statHtml.do?orgId=101\&tblId=DT_1J17135\&vw_cd=MT_ ZTITLE\&list_id=P2_6\&seqNo=\&lang_mode=ko\&language=kor\&obj_var_id=\&itm_id=\&conn_path=MT_ZTITLE (accessed on 14 August 2021).

33. Seoul Money Brokerage (Exchange Rate Statistics). Available online: http:/ / www.smbs.biz/Eng/ExRate/StdExRate.jsp (accessed on 14 August 2021).

34. Korea National Health and Nutrition Examination Survey (KNHANES VI-2); Ministry of Health, Welfare and Family Affairs: Sejong, Korea, 2015.

35. Beelen, R.; Stafoggia, M.; Raaschou-Nielsen, O.; Andersen, Z.J.; Xun, W.W.; Katsouyanni, K.; Dimakopoulou, K.; Brunekreef, B.; Weinmayr, G.; Hoffmann, B.; et al. Long-term Exposure to Air Pollution and Cardiovascular Mortality An Analysis of 22 European Cohorts. Epidemiology 2014, 25, 368-378. [CrossRef]

36. Cramer, J.; Jorgensen, J.T.; Hoffmann, B.; Loft, S.; Brauner, E.V.; Prescott, E.; Ketzel, M.; Hertel, O.; Brandt, J.; Jensen, S.S.; et al. Long-Term Exposure to Air Pollution and Incidence of Myocardial Infarction: A Danish Nurse Cohort Study. Environ. Health Perspect. 2020, 128, 57003. [CrossRef] [PubMed]

37. Gharibvand, L.; Shavlik, D.; Ghamsary, M.; Beeson, W.L.; Soret, S.; Knutsen, R.; Knutsen, S.F. The Association between Ambient Fine Particulate Air Pollution and Lung Cancer Incidence: Results from the AHSMOG-2 Study. Environ. Health Perspect. 2017, 125, 378-384. [CrossRef] [PubMed]

38. Guo, C.; Zhang, Z.; Lau, A.K.H.; Lin, C.Q.; Chuang, Y.C.; Chan, J.; Jiang, W.K.; Tam, T.; Yeoh, E.-K.; Chan, T.-C.; et al. Effect of long-term exposure to fine particulate matter on lung function decline and risk of chronic obstructive pulmonary disease in Taiwan: A longitudinal, cohort study. Lancet Planet. Health 2018, 2, e114-e125. [CrossRef]

39. Pun, V.C.; Kazemiparkouhi, F.; Manjourides, J.; Suh, H.H. Long-Term PM2.5 Exposure and Respiratory, Cancer, and Cardiovascular Mortality in Older US Adults. Am. J. Epidemiol. 2017, 186, 961-969. [CrossRef] [PubMed]

40. Turner, M.C.; Krewski, D.; Pope, C.A., 3rd; Chen, Y.; Gapstur, S.M.; Thun, M.J. Long-term ambient fine particulate matter air pollution and lung cancer in a large cohort of never-smokers. Am. J. Respir. Crit. Care Med. 2011, 184, 1374-1381. [CrossRef]

41. Cause of Death Statistics. Available online: https://kosis.kr/statHtml/statHtml.do?orgId=101\&tblId=DT_1B34E07\&conn_path= I3 (accessed on 16 October 2021).

42. Construction of National Surveillance System for Cardiovascular and Cerebrovascular Diseases; Health Insurance Review and Assessment Services: Wonju, Korea, 2006.

43. Trippoli, S.; Vaiani, M.; Lucioni, C.; Messori, A.; Quality-of-life Study Group of the Master 2 Project in Pharmacoeconomics. Quality of Life and Utility in Patients with Non-Small Cell Lung Cancer. Pharmacoeconomics 2001, 19, 855-863. [CrossRef]

44. Hwang, I.; Shin, D.W.; Kang, K.H.; Yang, H.K.; Kim, S.Y.; Park, J.H. Medical Costs and Healthcare Utilization among Cancer Decedents in the Last Year of Life in 2009. Cancer Res. Treat 2016, 48, 365-375. [CrossRef]

45. Clinical and Economic Evaluation of Statin Medication in Korea; Health Insurance Review and Assessment Service: Wonju, Korea, 2009.

46. Kim, J.; Henderson, R.A.; Pocock, S.J.; Clayton, T.; Sculpher, M.J.; Fox, K.A.; Investigators, R.-T. Health-related quality of life after interventional or conservative strategy in patients with unstable angina or non-ST-segment elevation myocardial infarction: One-year results of the third Randomized Intervention Trial of unstable Angina (RITA-3). J. Am. Coll. Cardiol. 2005, 45, 221-228. [CrossRef]

47. Darlington, A.S.; Dippel, D.W.; Ribbers, G.M.; van Balen, R.; Passchier, J.; Busschbach, J.J. Coping strategies as determinants of quality of life in stroke patients: A longitudinal study. Cerebrovasc. Dis. 2007, 23, 401-407. [CrossRef]

48. Kang, K.S.; Na, S.O.; Yu, Y.B.; Shin, J.H. The Quality of Life in COPD Patients according to Gender: Based on the 4th Korea National Health and Nutrition Examination Survey. J. Korean Acad. Community Health Nurs. 2015, 26, 61-68. [CrossRef]

49. Sun, D.; Cao, M.; Li, H.; He, S.; Chen, W. Cancer burden and trends in China: A review and comparison with Japan and South Korea. Chin. J. Cancer Res. 2020, 32, 129-139. [CrossRef]

50. Huang, K.; Liang, F.; Yang, X.; Liu, F.; Li, J.; Xiao, Q.; Chen, J.; Liu, X.; Cao, J.; Shen, C.; et al. Long term exposure to ambient fine particulate matter and incidence of stroke: Prospective cohort study from the China-PAR project. BMJ 2019, 367, 16720. [CrossRef]

51. Lifetable. Available online: https:// kosis.kr/statHtml/statHtml.do?orgId=101\&tblId=DT_1B41\&conn_path=I3 (accessed on 9 August 2021).

52. Yin, H.; Pizzol, M.; Xu, L. External costs of PM2.5 pollution in Beijing, China: Uncertainty analysis of multiple health impacts and costs. Environ. Pollut. 2017, 226, 356-369. [CrossRef]

53. Lim, Y.H.; Oh, J.; Han, C.; Bae, H.J.; Kim, S.; Jang, Y.; Ha, E.; Hong, Y.C. Long-term exposure to moderate fine particulate matter concentrations and cause-specific mortality in an ageing society. Int. J. Epidemiol. 2021, 49, 1792-1801. [CrossRef]

54. Kim, T.-Y.; Kim, H.; Yi, S.-M.; Cheong, J.-P.; Heo, J. Short-term Effects of Ambient PM2.5 and PM2.5-10 on Mortality in Major Cities of Korea. Aerosol Air Qual. Res. 2018, 18, 1853-1862. [CrossRef]

55. Ran, J.; Schooling, C.M.; Han, L.; Sun, S.; Zhao, S.; Zhang, X.; Chan, K.P.; Guo, F.; Lee, R.S.; Qiu, Y.; et al. Long-term exposure to fine particulate matter and dementia incidence: A cohort study in Hong Kong. Environ. Pollut. 2021, 271, 116303. [CrossRef] 
56. Karimi, A.; Shirmardi, M.; Hadei, M.; Birgani, Y.T.; Neisi, A.; Takdastan, A.; Goudarzi, G. Concentrations and health effects of short- and long-term exposure to $\mathrm{PM} 2.5, \mathrm{NO}_{2}$, and $\mathrm{O}_{3}$ in ambient air of Ahvaz city, Iran (2014-2017). Ecotoxicol. Environ. Saf. 2019, 180, 542-548. [CrossRef]

57. Liang, F.; Xiao, Q.; Gu, D.; Xu, M.; Tian, L.; Guo, Q.; Wu, Z.; Pan, X.; Liu, Y. Satellite-based short- and long-term exposure to PM2.5 and adult mortality in urban Beijing, China. Environ. Pollut. 2018, 242 Pt A, 492-499. [CrossRef]

58. Ohlwein, S.; Kappeler, R.; Kutlar Joss, M.; Kunzli, N.; Hoffmann, B. Health effects of ultrafine particles: A systematic literature review update of epidemiological evidence. Int. J. Public Health 2019, 64, 547-559. [CrossRef]

59. Weichenthal, S. Selected physiological effects of ultrafine particles in acute cardiovascular morbidity. Environ. Res. 2012, 115, 26-36. [CrossRef] 